\title{
The Reasons Why Women Prefer C-Sections, Their Knowledge, Behavior and Attitudes towards Abortion
}

\author{
Senay Cetinkaya \\ Department of Nursing, Child Health and Nursing, Faculty of Health Sciences, Çukurova University, Adana, Turkey \\ Email: senayg_202@hotmail.com, scetinkaya@cu.edu.tr
}

How to cite this paper: Cetinkaya, S. (2020) The Reasons Why Women Prefer C-Sections, Their Knowledge, Behavior and Attitudes towards Abortion. Open Journal of Obstetrics and Gynecology, 10, 221-236. https://doi.org/10.4236/ojog.2020.1020019

Received: December 2, 2019

Accepted: February 9, 2020

Published: February 12, 2020

Copyright $\odot 2020$ by author(s) and Scientific Research Publishing Inc. This work is licensed under the Creative Commons Attribution International License (CC BY 4.0).

http://creativecommons.org/licenses/by/4.0/

(c) (i) Open Access

\begin{abstract}
Background: This research was carried out in Turkey between $20^{\text {th }}$ of April 2008 and $20^{\text {th }}$ June 2008 to women coming to childbirth and healthy child care outpatient polyclinics, public hospitals, and respective polyclinics in Adana city. Methods: This work of cross sectional study type was conducted to discover different reasons why women prefer C-section or normal delivery and knowledge, behavior, and attitude toward abortion. The questionnaire, which was developed by using the literature, was applied face to face with 395 people verbally approved. Results: $65.1 \%$ (257) of the women had no miscarriages, $54.2 \%$ (214) had one or two pregnancies and the mean number of pregnancies was $2.84 \pm 2.01$. While $74(18.7 \%)$ of the women had 1 normal birth, 148 (37.5\%) had 1 cesarean birth. While 203 (51.4\%) of the women prefer cesarean on their own will, $32(8.1 \%)$ stated that they had to make cesarean for medical reasons. 293 (75\%) of the women stated that they had at least 1 cesarean delivery around them. Normal vaginal birth was mostly preferred by housewives. 263 (66.6\%) of the women stated that they did not have any abortions and $132(33.4 \%)$ stated that they had abortion at least once. Sixty percent of the women stated that they did not find the curettage correct. The difference between reasons why women prefer caesarean section and gynecology obstetric clinics doing it was significant $(\mathrm{p}<0.05)$. Statistically significant difference was found between finding the right of abortion and having abortion $(p<0.05)$. Conclusions: Participating women on average have had a normal birth and once a cesarean delivery, and at least 3 women around each woman seem to have had a cesarean delivery. One of every two females seems to have had an abortion. Effective family planning training should be provided.
\end{abstract}

\section{Keywords}

Caesarean, Abortion, Knowledge, Attitude, Practice, Nursing 


\section{Introduction}

In September 2000, 187 countries attend the summit meeting of the millennium in which they adopted the MDGs (Millennium Development Goals) together to eradicate poverty alleviation. Over the following years, the International Conference on Population and Development (ICPD) adopted a list of 17 indicators that monitor reproductive health goals [1].

According to UNFPA (United Nations Population Fund in the World)'s special committee of twenty-first private session for 1990, 1995 and 2000; more than half the million women die each year. Most of them die from pregnancy and birth difficulties, more than $40 \%$ in Asia and 50\% in Africa [1]. In Turkey, every day one mother and 120 babies die from preventable causes. The average of one in four births in Turkey is made without ever taking a pre-pregnancy health care [2].

The MDGs cover several goals in the field of sexual and reproductive health. Universal methods of safe and effective family planning, including the widest range of barrier methods up to 2015 , followed by appropriate reproductive health services; prevention and management of reproductive system infections, including sexually transmitted infectious diseases, is essential for pregnancy-related care [1]. The Millennium Development's Objectives mention Turkey among countries unable to follow the 5 indications where in 2000-2006 at least women aged 15 - 49 went 4 times for antenatal care, 54\% (64\% in urban, while $33 \%$ in the rural areas), at least 1 and $83 \%$ for antenatal care [3]. In Turkey, $78 \%$ of births are given in a health institution. This proportion drops to $60 \%$ in some regions. Over 100 married couples, only 43 use modern contraceptive methods [2].

Reproductive health is a condition of full physical, mental and social well-being and is not merely the absence of disease or weakness, in essence depends on the reproductive system, tasks and processes. Therefore, reproductive system involves people having a safe health reproductive organs, life, satisfaction and being free to decide when and how often they will have the ability to proliferate. At the same time, it includes sexual health, which is the purpose of the increase in personal life and relationships. Reproductive age includes all women aged 15 49 [1]. In Turkey, 78 out of a hundred births can be performed in a health institution [4]. Turkey's population will reach 100 million in 2050 and will cover approximately one quarter of the EU population [2].

Despite of being one of the most common surgeries in the world: The cesarean section is still considered to be one of the risky surgeries. However, in any case where the mother or the baby's life is in danger, delivery should be done with caesarean section [5]. Cesarean section; an incision is made in the abdomen and the baby is surgically removed from uterus [6].

Abortion; means getting out tissue through the uterus. It is usually done to end your pregnancy with a special method. The abortion procedure is also used as a diagnostic biopsy or treatment for the purpose other than pregnancy termi- 
nation. It is expressed in the medical language as D\&C (dilation and curettage) [7].

According to 2005 WHO's report, 50 million women abortion each year in the world. Every day more than 200 women lose their lives while trying to take care of a child in their belly. The situation is very different in Turkey. According to TNSA 2003 report, Turkey had requested quits for 15 out of every 100 pregnancies [8]. 76 percent of married couples do not want a new child [4]. Rates of abortion are also given according to report age groups, which indicates that the rate of abortion in Turkey has increased rapidly compared to other countries. The abortion rate is $6 \%$ in the $15-19$ age group, $7 \%$ in the $20-24$ age group, $20 \%$ in the $25-29$ age group, $27 \%$ in the $30-34$ age group, $38 \%$ in the $35-44$ age group and 45 - 49 age group is $42 \%$ [9].

It could be said that the proportion of healthy babies born by planed normal vaginal route in the world and in Turkey is not at the desired level. However, since the rate of using effective family planning method is low in Turkey, it can be said that abortion is used as a contraceptive method in terminating unwanted pregnancies. It is important for women to determine their knowledge, attitudes in achieving the goals set out in the MDGs. In this context, this study was planned by taking into account the fact that in this respect nurses can understand women and make effective educational activities.

The purpose of this study is; women's cesarean or normal birth preferences, their knowledge, attitudes, behaviors and thoughts about abortion.

\section{Materials and Methods}

This research was carried out in Turkey to women coming to childbirth to gynecological and obstetric clinics and pediatric outpatient clinics in public hospitals, and respective polyclinics in Adana city. This work of cross sectional study type was conducted to discover different reasons why women prefer C-section or normal delivery and knowledge, behavior, and attitude toward abortion.

This study was carried out in Çukurova University Medical Faculty Balcalı Hospital department of obstetrics and gynecology, obstetrics and gynecology clinic of Adana, birth and childcare hospital, Adana Çukurova maternity and childcare hospital. It was held between 20.04.2008-20.06.2008. These questionnaires were administered to every woman who wanted to participate in the study. 395 people participated in the survey were asked face to face on the dates mentioned above. 124 of participants were in the Marsa gynecology obstetric clinic, 77 of Meydan gynecology obstetric clinic and 194 of Balcalı hospital.

As a data collection technique, a questionnaire was developed by using the literature and was applied face to face. The research questionnaire was prepared with literature surveys. Preliminary application was performed and they were not included in the study. The questionnaire consisted of 27 questions in total. The first 5 questions in the questionnaire were related to socio-demographic information and the remaining questions were about cesarean and knowledge, behaviors and attitudes toward abortion. The participants; were asked how many 
times they aborted, cesarean or abortion decisions, whether they are influenced by their emotions, or if they should have an abortion due to various reasons, if they will do so or not, whether they have found the right curettage, whether it is legal until the 10th week, whether o it will harm them physiologically or not and so on (Table 1).

The data analysis was evaluated by the percentage of the SPSS program in the computer by using the chi-square analysis method.

Çukurova University Medical Faculty Ethics Committee approval was obtained.

Table 1. Survey Form: women's choice of cesarean birth and knowledge attitude and behavior about abortion/curettage.

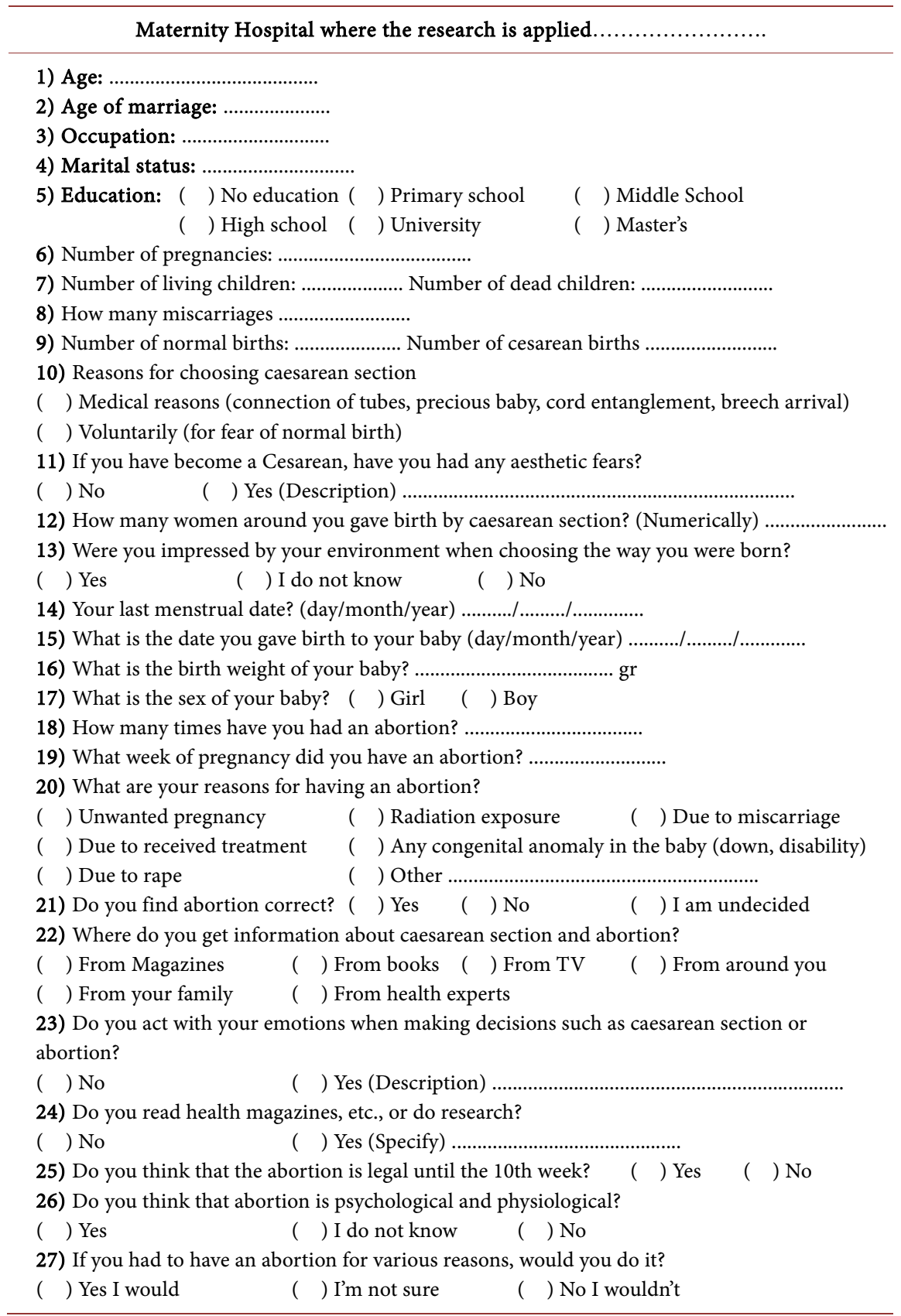




\section{Results}

The ages of women participating in the survey ranged from minimum 17 to maximum 52. The average age is $27.97 \pm 5.89$. The marriage ages ranged from a minimum of 12 to a maximum of 40 . The average age of marriage is $21.03 \pm$ 4.44 .

$85 \%$ of the participants were housewives and $15 \%$ were from other occupational groups. 10 of them were civil servants and 14 of them were from nursing and midwifery professions. The educational status of women is shown in Table 3.

The mean number of pregnancies was $2.84 \pm 2.01$ (Table 2), 1.69 of children were living, 0.46 died and 0.54 were aborted. $54.2 \%$ of the respondents had 1 or 2 pregnancies. 2 participants 10, 2 participants 11,2 participants 12 and 1 participant had 15 gestations. $21.5 \%$ of the participants did not have any living child, $29.4 \%$ had 1 living child, and $26.3 \%$ had 2 living children. There was also one participant with 11 living children. $65.1 \%$ of participants did not have any abortion. $22.8 \%$ had 1 and $8.4 \%$ had 2 abortions. And 1 participant had had 8 abortions.

$54.2 \%$ of the respondents had 1 or 2 pregnancies and 2 of them had 10, 2 of them had 11, 2 of them had 12 and 1 of them had 15 pregnancies.

While $18.7 \%$ of the participants had 1 normal birth, $37.5 \%$ had 1 cesarean birth. Two people had 4 cesarean deliveries. While $51.4 \%$ of the participants chose cesarean on their own will, $8.1 \%$ had to have a cesarean section for medical reasons. The reasons for most of these cesareans are due to breech or tubal ligation (Table 4).

The birth weights of the babies of participants ranged from a minimum of 1800 gr and a maximum of 4600 gr. The average weight was $3287.02 \pm 493.618$

Table 2. Distribution of findings of women participating in the survey.

\begin{tabular}{|c|c|c|}
\hline Variable $(\mathrm{N}=395)$ & $\mathrm{N}$ & $\%$ \\
\hline The average age of a women & \multicolumn{2}{|c|}{$27.97 \pm 5.89$} \\
\hline The average age of marriage & \multicolumn{2}{|c|}{$21.03 \pm 4.44$} \\
\hline The number of pregnancies were & \multicolumn{2}{|c|}{$2.84 \pm 2.01$} \\
\hline \multicolumn{3}{|l|}{ Education level of women } \\
\hline Not literate & 51 & 12.9 \\
\hline Primary school graduates & 149 & 37.7 \\
\hline Secondary school graduates & 56 & 14.2 \\
\hline High school graduates & 99 & 25.1 \\
\hline Graduated from a University & 2 & 0.5 \\
\hline Post Graduates (masters) & 38 & 9.6 \\
\hline \multicolumn{3}{|l|}{ The hospital where the women are } \\
\hline Cukurova University Faculty of Medicine Balcalı Hospital & 194 & 49.1 \\
\hline Adana Cukurova Birth and Child Care Hospital & 124 & 31.4 \\
\hline Adana Birth and Child Care Center & 77 & 19.5 \\
\hline Total & 395 & 100 \\
\hline
\end{tabular}


gr. 4 of these babies had low birth weight. $53.7 \%$ of infants were male and $46.3 \%$ were female.

$263(66.6 \%)$ of the women did not have any abortions and $132(33.4 \%)$ had at least one abortion. The woman mentioned before had 8 abortions.

Twenty-five percent of women reported abortion after 8 weeks and 21 percent after 10 weeks. $60 \%$ of the participants do not find the abortion correct.

$11 \%$ of respondents said they had information about the cesarean and abortion from the magazines, $12 \%$ from the books, $23 \%$ from TV, $36 \%$ from the environment, $20 \%$ from the family and $70 \%$ health care professional.

$60 \%$ of the women did not affected by emotions when they decided to make a decision about cesarean and abortion. 55\% of the women stated that they did not do any research and did not get any information. $51 \%$ of the women stated that they found the curettage right until the 10th week. $90 \%$ of women think that abortion is harmful and 55\% say they can make an abortion if there no other option.

The distribution of the women participating in the survey according to hospitals they preferred at the time of the research is shown in Table 2.

The examination of the hospitals that women preferred according to their educational status is shown in Table 3. 51\% of high school graduates and $67 \%$ of university graduates preferred Balcalı hospital. Statistically significant differences were found between the education status of the women and the hospitals they preferred ( $\mathrm{p}=0.026, \mathrm{p}<0.05)$ (Figure 1) (Table 2).

$59 \%$ of the 32 people who preferred cesarean on their own behalf performed birth at Marsa gynecology obstetric clinic. $45.8 \%$ of those who preferred cesarean for medical reasons gave birth in Balcalı hospital. The difference between

Table 3. Examination the hospitals that women refer to according to their educational status.

\begin{tabular}{cccccc}
\hline \multirow{2}{*}{ EDUCAITON LEVEL } & & \multicolumn{3}{c}{ HOSPITALS } & \multirow{2}{*}{ TOTAL } \\
\cline { 3 - 5 } Not literate & & MARSA & MEYDAN & BALCALI & \\
\hline & $\mathrm{N}$ & 11 & 16 & 24 & 51 \\
Primary school graduate & $\mathrm{N}$ & $21.6 \%$ & $31.4 \%$ & $47.1 \%$ & $100.0 \%$ \\
& $\%$ & $42.2 \%$ & $22.8 \%$ & $45.0 \%$ & $100.0 \%$ \\
Secondary school graduates & $\mathrm{N}$ & 22 & 9 & 25 & 56 \\
& $\%$ & $39.3 \%$ & $16.1 \%$ & $44.6 \%$ & $100.0 \%$ \\
High school graduate & $\mathrm{N}$ & 32 & 16 & 51 & 99 \\
& $\%$ & $32.3 \%$ & $16.2 \%$ & $51.5 \%$ & $100.0 \%$ \\
University graduate & $\mathrm{N}$ & 11 & 2 & 27 & 40 \\
& $\%$ & $27.5 \%$ & $5.0 \%$ & $67.5 \%$ & $100.0 \%$ \\
TOTAL & $\mathrm{N}$ & 124 & 77 & 194 & 395 \\
& $\%$ & $31.4 \%$ & $19.5 \%$ & $49.1 \%$ & $100.0 \%$ \\
\hline
\end{tabular}




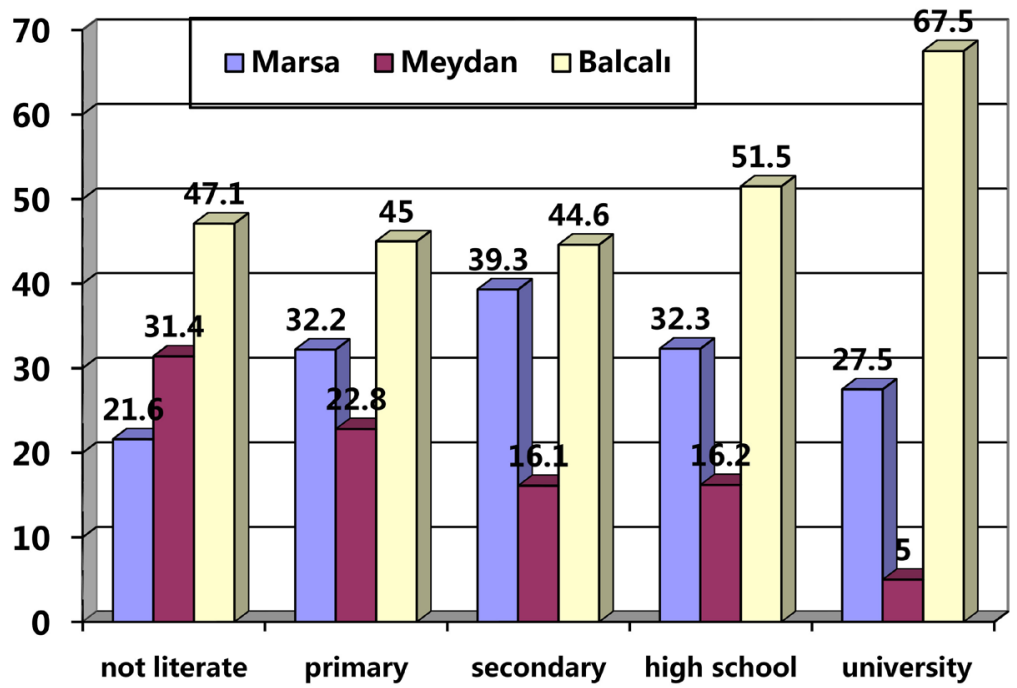

Figure 1. Educational status of participants according to hospitals $(\mathrm{p}=0.026, \mathrm{p}<0.05)$.

the ones who preferred cesarean on their own request and the hospital they applied was found to be statistically significant ( $\mathrm{p}=0.001, \mathrm{p}<0.05)$ (Figure 2).

Individuals with fears for caesarean section showed a similar distribution in all 3 hospitals and no significant difference was found between them ( $p>0.05)$.

$77 \%$ of those who did not know whether they were affected by their surroundings when choosing the way of birth gave birth in Marsa birth home.

While $68 \%$ (28 people) of unwanted pregnancies terminated their pregnancy at Marsa birth home, 18\% (5 people) ended in Balcalı hospital. 29\% (27 people) of the abortions were aborted due to miscarriages, $15 \%$ (14 people) were in Meydan gynecology obstetric clinic and 56\% (52 people) were in Balcalı hospital. It is seen that 9 out of 16 pregnancies terminated due to any congenital anomaly are in Balcalı hospital and 7 are in Marsa gynecology obstetric clinic. The difference was statistically significant between the patients whose pregnancies were terminated due to unintended pregnancy $(\mathrm{p}=0.001, \mathrm{p}<0.05)$ (Figure 3 ). The difference was statistically significant between the patients whose pregnancies were terminated due to abortion ( $p=0.002, p<0.05)$ (Figure 3 ). Termination of pregnancies due to congenital anomalies was not significant $(p=0.084, p>0.05)$ (Figure 3).

Those who found the right of abortion-those who did not found similar distribution among the hospitals and there was no significant difference between them $(\mathrm{p}>0.05)$.

Most of the acquisitions of information from magazines (55.8\%), books (71.1\%) and television (60\%) came to the Balcalı hospital. In addition, the majority of those who came to Balcalı's hospital were informed by doctors (51.6\%). Most of those who get information from their families are those who go to the Meydan gynecology obstetric clinic (40.3\%) and those who get the most information from their surroundings prefer Marsa gynecology obstetric clinic (38.9\%).

The difference between the hospitals preferred by the health specialists of the 


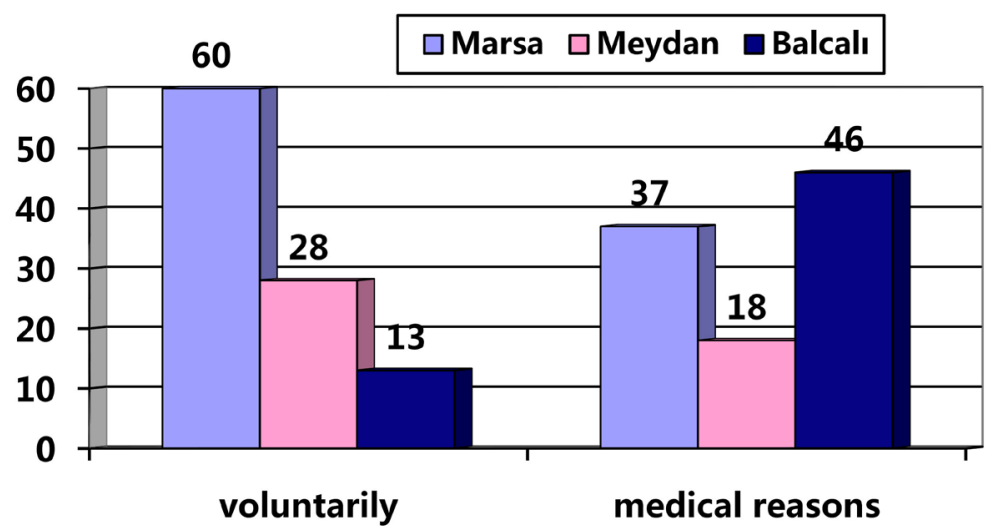

Figure 2. Reasons of preffering cesarean according to birth centers $(\mathrm{p}=0.001, \mathrm{p}<0.05)$.

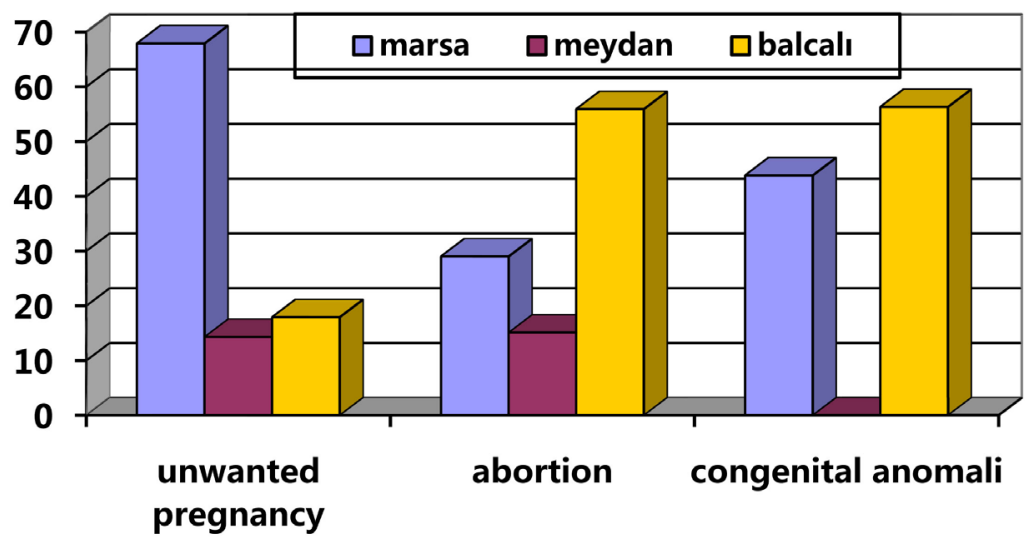

Figure 3. The distribution of different reasons of abortion according to hospitals $(\mathrm{p}=$ $0.001, \mathrm{p}<0.05)(\mathrm{p}=0.002, \mathrm{p}<0.05)(\mathrm{p}=0.084, \mathrm{p}>0.05)$.

participants in the study was not statistically significant $(\mathrm{p}=0.426, \mathrm{p}>0.05)$ (Figure 4). But the difference between the family ( $p=0.001, p<0.05)$, the periphery $(\mathrm{p}=0.032, \mathrm{p}<0.05)$, the television $(\mathrm{p}=0.023, \mathrm{p}<0.05)$ and the hospitals preferred by those who received information from books $(\mathrm{p}=0.001, \mathrm{p}<0.05)$ and magazines ( $p=0.003, p<0.05)$ was significant (Figure 4$)$.

It was also determined that the majority of those who acted with emotion about caesarean section and abortion (49.7\%) were women who came to Balcalı hospital.

$60 \%$ of the researchers who got information about caesarean section and abortion came to Balcalı hospital. There were no significant differences between the patients who visited the 3 hospitals and whether they were correct until 10th week $(\mathrm{p}>0.05)$.

Those who thought that the caesarean was harming the woman gave similar responses to all three hospitals and in general 351 of the 395 people answered yes, and if they had to do so, the majority of them would come to the Balcalı hospital (63.8\%). The majority of those who did not do it were those who came to Marsa's gynecology obstetric clinic (38.9\%).

$45.6 \%$ of those who did not find the abortion correctly stated that they would 


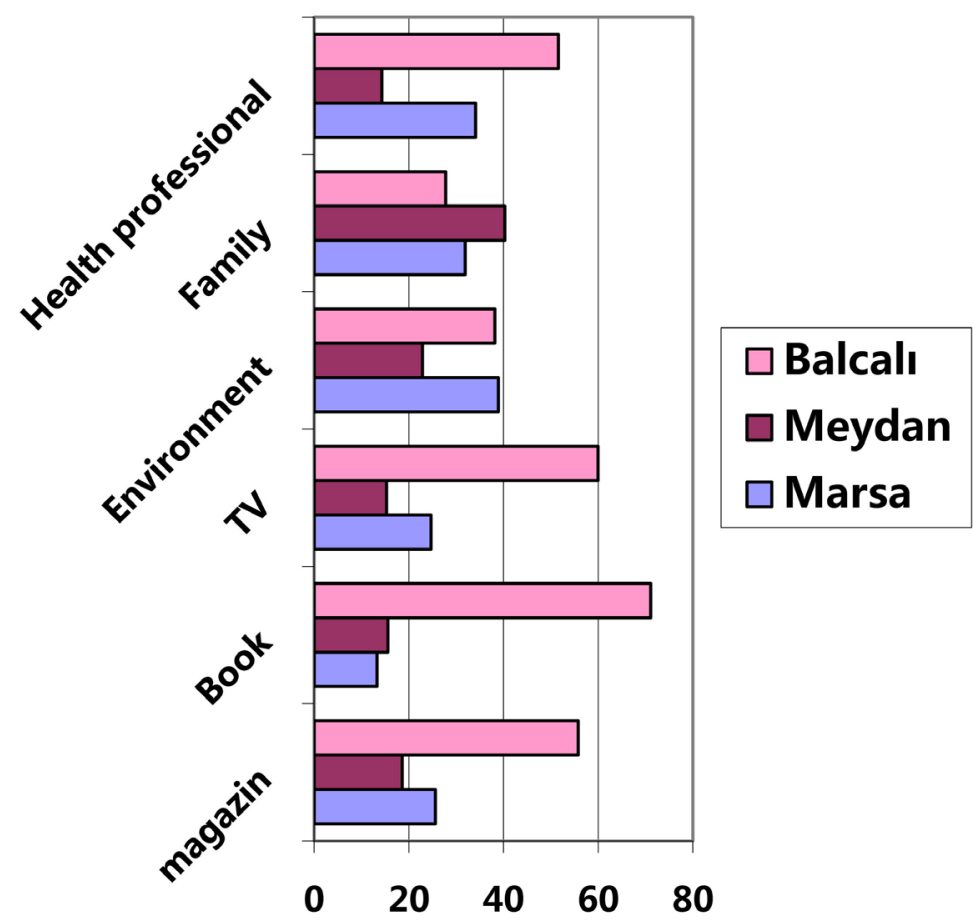

Figure 4. Where participants got information according to birth centers $(\mathrm{P}=0.426, \mathrm{p}>$ $0.05)(\mathrm{p}=0.001, \mathrm{p}<0.05)(\mathrm{p}=0.032, \mathrm{p}<0.05)(\mathrm{p}=0.023, \mathrm{p}<0.05)(\mathrm{p}=0.001, \mathrm{p}<0.05)$ $(\mathrm{p}=0.003, \mathrm{p}<0.05)$.

not do it even if they had to stay in it and $46.4 \%$ would do it if they were forced. Those who are unsure have stated that they can make $45 \%$. The difference between finding an abortion correctly and having an abortion was statistically significant $(\mathrm{p}=0.001, \mathrm{p}<0.05)($ Figure 5$)$.

On average, women who participated in the survey had a normal birth and once a cesarean delivery, and at least 3 women around each woman seem to have had a cesarean delivery. One of every two females seems to have had an abortion.

We have already stated that $85 \%$ of the participants are housewives. The majority of housewives (42.2\%) completed elementary school. Most of the university graduates $(51.8 \%)$ are working and $3.2 \%$ are housewives.

$46 \%$ of the group of housewives in the survey preferred Balcalı hospital, $31.6 \%$ of Marsa gynecology obstetric clinic and $22.4 \%$ of Meydan gynecology obstetric clinic. Of the group of employees, $67.9 \%$ preferred Balcalı hospital, $48 \%$ preferred Meydan gynecology obstetric clinic and 30.4\% preferred Marsa gynecology obstetric clinic. The difference between the working status of the women (housewife and employees) and the preferred hospital was statistically significant $(\mathrm{p}=0.001, \mathrm{p}<0.05)$ (Figure 6).

The majority of those who prefer cesarean section among participants are employees in any profession group (76.2\%). Normal birth was mostly preferred by housewives (33.1\%). The majority of those who did not find the right to abortion were housewives (63.2\%), those who find it right are employees (44.6\%). 


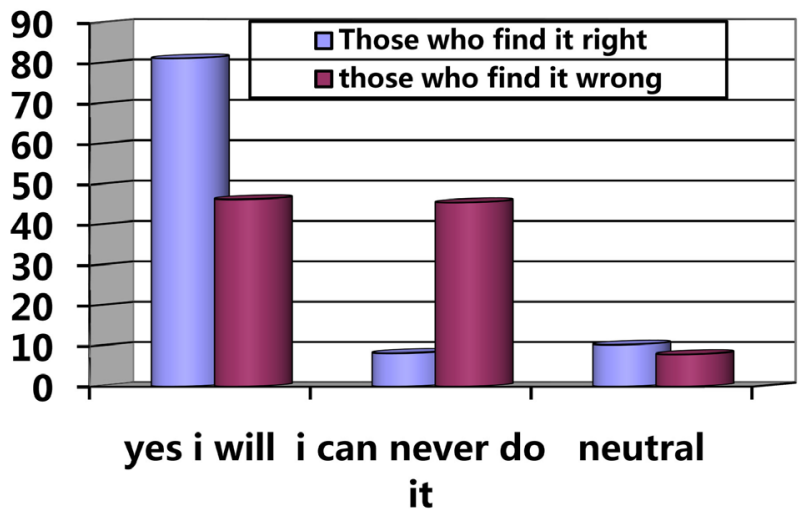

Figure 5. Abortion rates for those who find the right abortion and those who cannot $(\mathrm{p}=$ $0.001, \mathrm{p}<0.05)$.

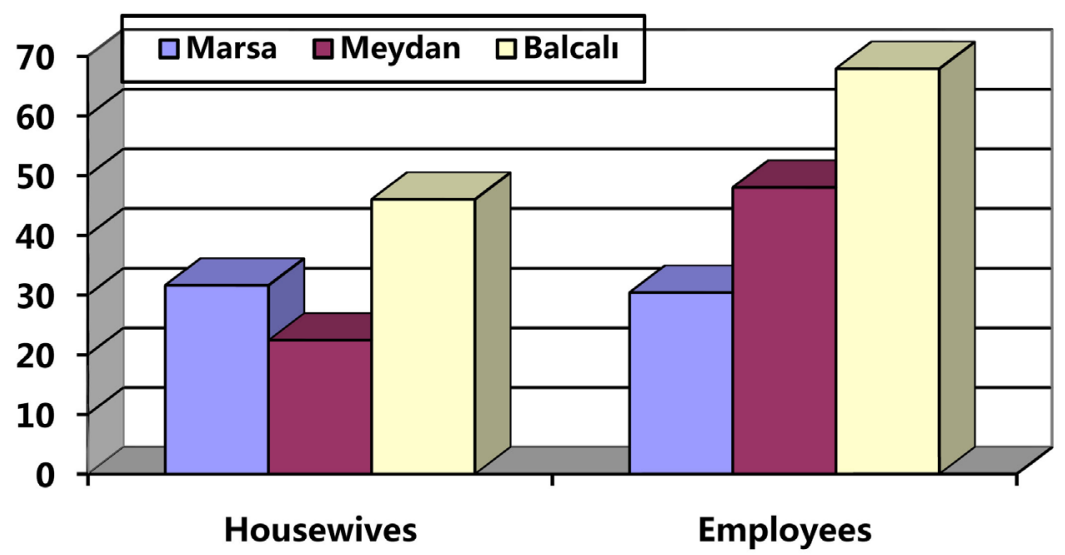

Figure 6. The reasons of preferring different birth centers for housewives and employees $(\mathrm{p}=0.001, \mathrm{p}<0.05)$.

$22.2 \%$ of the employees were informed from the magazines; $10 \%$ of housewives learn from magazines, and $90 \%$ of housewives know neither magazines nor books. Only $27 \%$ of employees get information from books. While $21 \%$ of housewives were informed on television, $35 \%$ of employees were informed on television. The rate of acquiring information from the periphery is similar in both groups. The majority of those who learn from their family (22.4\%) were housewives. $5.5 \%$ of the employees were informed by their family members. While $41.8 \%$ of housewives indicated that they did research while they were informed, $67.9 \%$ of the employees stated that they did research.

While $50 \%$ of those who found the abortion until the 10th week were housewives, $64 \%$ were working. The housewives had a normal birth of $1.09 \pm 1.53$ while, were found mean of $0.79 \pm 0.87$ were cesarean deliveries. The employees had a normal birth was $0.41 \pm 0.65$ while, were found mean of $0.75 \pm 0.74$ cesarean deliveries.

The educational status of the women participating in the study significantly affected the hospital $(\mathrm{p}=0.026, \mathrm{p}<0.05)$ and the working conditions of the women affected the preferred birth home $(\mathrm{p}=0.001, \mathrm{p}<0.05)$ (Figure 1$)$. 
The difference between women's cesarean section preference and maternity home was significant ( $\mathrm{p}=0.001, \mathrm{p}<0.05$ ) (Figure 2 ). A statistically significant difference was also found between finding the right abortion and having an abortion $(\mathrm{p}=0.001, \mathrm{p}<0.05)$ (Figure 5).

\section{Discussion}

$85 \%$ of participants are housewives and $15 \%$ are from different occupational groups. Yildiz et al. work conducted in 2014, 78.5\% of participants were housewives [10].

In this reaserch, $12.9 \%$ of the women are not literate, $37.7 \%$ are primary, $14.2 \%$ are middle school, $25.1 \%$ are high school graduates and $10.1 \%$ are university and graduates (Table 2). Unlike the study by Yildiz et al. (2014), 24\% of women are illiterate, $61.3 \%$ are primary school graduates, $8.3 \%$ are high school graduates and $6.5 \%$ are college graduates [10]. It is shown that the educational status of women line up with research findings.

In terms of life saving of mother and baby compared cesarean to vaginal birth, cesarean increased fourfold maternal mortality and morbidity rates. It also has disadvantages such as high maternal mortality and delays recovery, breastfeeding and maternal-fetal relationship and also increases risk of risky pregnancy in the future births. In addition, 50\% more money is spent on cesarean operations compared to vaginal birth, and the economic cost increases due to the longer stay in hospital [11].

Despite of all of these disadvantages, cesarean rates have increased rapidly over the last thirty years in almost all parts of the world. There are many factors that cause this increase, the most important one is the elective cesarean delivery after the cesarean birth [11]. Cesarean section rates are increasing rapidly and the indications are increasing day by day. This trend not only in Turkey but also in the world. For this reason, the rate of cesarean section in private hospitals is much more [5]. According to 2003 Turkey Demographic and Health Survey (TDHS), Considering the recent birth months of caesarean section rate 21.2 per cent, 40 per cent of cesarean delivery rate is in the EU countries and the United States. In this context, on the target set by the WHO (5\% - 15\%) [12]. It is mentioned that $36.7 \%$ in 2008 TDHS [11] [13]. As of 2011, this ratio is announced as $48 \%$ [14]. In the survey conducted by Özkaya at Süleyman Demirel University Faculty of Medicine; the average cesarean rate during the 5 years (1998-2002) was $53.7 \%$ [15].

While $18.7 \%$ of the participants had 1 normal birth, $37.5 \%$ had 1 cesarean birth. Two people had 4 cesarean deliveries Güngör et al. 2013. In a study conducted in a university hospital in Istanbul in 2003, it was determined that $17.9 \%$ of women had only normal birth, 30.4\% had only cesarean birth, and $8 \%$ had both normal and cesarean births [16]. Similar findings are observed in terms of normal birth. The rate of caesarean section is slightly elevated because may be it took five years between the implementation of two researches. 
It is important that the American Academy of Obstetrics and Gynecology (ACOG) explain cesarean indications and its outcomes by recalling that it is due to medical reasons rather than depending on demand [12].

While $51.4 \%$ of the participants chose cesarean on their own initiative, $8.1 \%$ cesarean had to be done for medical reasons. The reasons for most of these cesareans are that the baby is coming breech or tube ligation (Table 4). It is realized that the research findings are in accordance with the ACOG proposal. In the study conducted by Yildiz et al. (2014) 87\% of participants preferred normal birth and 13\% preferred cesarean births. Group 3 (at least one cesarean birth) was also a request for tube ligation while group 1 (who did not give birth earlier) preferred it more comfortably and easily. Less pain and episiotomy fear were other main reasons [10].

In the research conducted by Yalınkaya et al. (2003), it was determined that old cesarean section, elective cesarean section and fetal distress showed the greatest increase $(\mathrm{p}<0.001)$. While the ratio of the old cesarean section was less than $20 \%$ until 1994, it increased from 1995 to $30.2 \%$ in 2002 [17]. In the research

Table 4. The distribution of the number of women who participated in the study, cesarean delivery preference reasons, fear causes and abortion numbers.

\begin{tabular}{|c|c|c|}
\hline Number of cesarean births $(\mathrm{N}=395)$ & $\mathrm{N}$ & $\%$ \\
\hline no caesarean section & 175 & 44.3 \\
\hline 1 caesarean section & 148 & 37.5 \\
\hline 2 caesarean section & 56 & 14.2 \\
\hline 3 caesarean section & 14 & 3.5 \\
\hline 4 caesarean section & 2 & 0.5 \\
\hline \multicolumn{3}{|l|}{ Cesarean delivery preference reasons $(\mathrm{N}=395)$} \\
\hline medical reasons & 32 & 8.1 \\
\hline voluntarily & 203 & 51.4 \\
\hline unresponsive & 160 & 40.5 \\
\hline \multicolumn{3}{|l|}{$\begin{array}{c}\text { If you have become a Cesarean, } \\
\text { have you had any aesthetic fears? }(\mathrm{N}=395)\end{array}$} \\
\hline Yes & 69 & 17.5 \\
\hline No & 169 & 42.8 \\
\hline Unresponsive & 157 & 39.7 \\
\hline \multicolumn{3}{|l|}{ Abortion numbers $(\mathrm{N}=395)$} \\
\hline never miscarried & 257 & 65.1 \\
\hline 1 Miscarriage & 90 & 22.8 \\
\hline 2 Miscarriage & 33 & 8.3 \\
\hline 3 Miscarriage & 8 & 2.0 \\
\hline 4 Miscarriage & 6 & 1.5 \\
\hline 8 Miscarriage & 1 & 0.3 \\
\hline
\end{tabular}


that Yalınkaya et al. conducted, it is similar to the research findings that old cesarean section, cesarean section indications causes, and meaningfulness are significant. In the survey conducted in $2008,37.5 \%$ of the women had 1 cesarean birth. It is seen that is similar and increased compared to the 2002 data [17]. In this study, the rate of cesarean section $37.5 \%$ is similar to the data in 2008 TDHS (36.7\%) [10] [13] [18].

The majority of those who prefered cesarean section among participants are employees in any profession group (76.2\%). Normal birth was mostly preferred by housewives (33.1\%). Similarly, in the Yıldiz et al. study, monthly income growth was found to affect cesarean delivery preference [10]. At the same time, older age and increasing in number of spouses are also effective in cesarean preference. In the Sayiner et al. study, $61 \%$ of women who prefer to have normal births did not work [19]. Güngör et al. the proportion of women with high education level and primiparity was significantly higher than that of women with cesarean section $(\mathrm{p}<0.05)$.

One in every 4 or 5 babies is born with a cesarean [1]. Cesarean rates vary depending on non-medical factors. Cesarean rate is higher among women with private health insurance, older, married, high socio-economic and cultural level [20]. Cesarean section is much more prevalent in mothers over age 30 and in higher education mothers [1].

Yalınkaya et al. (2003) conducted a retrospective study of 6.144 births and 6.124 caesarean sections in Diyarbakır at the Dicle University Medical Faculty, Obstetrics and Gynecology Clinic between January 1, 1983 and December 31, 2002. The total number of births per year was 573 to 1.655 , and cesarean rate was found to vary between $17.2 \%$ and $50.4 \%$. It has been observed that the rate of caesarean is increasing with the years [17].

According to the General Directorate of Mother and Child Health and Family Planning, factors such as increase of demand-dependent and repeated cesarean sections and enlargement of indications play a role in the reasons for raising the cesarean rate [12] [17]. In addition, risks of anesthesia, used drugs and materials, surgical and postoperative care decreases mortality and cesarean related deaths and diseases but still infections, hemorrhage, transfusion need, thromboembolic risks, longer hospital stay, healing later [12]. The caesarean may delay the interaction between the mother and the newborn, causing problems in breastfeeding and maintaining family ties. Elective caesarean section leads to premature birth and respiratory distress syndrome in the baby, leading to many complications, resulting in intensive care and increased medical costs [20].

The American Association of Gynecologists and Obstetricians recommends that two or more cesarean births should not break the courage of women who wish to give birth through a vaginal route, with a low transverse cross-section and no contraindications [20]. In some cases, indeed, normal vaginal delivery is unexpected and caesarean section should be done [21].

In fact, while determining the way of birth for the baby and mother who are 
about to open their eyes to the world, considering the advantages and disadvantages of cesarean section or normal birth; the doctor and the family should decide together [21]. The necessary information about this subject should be given to the mother, the risks of the pre-implementation intervention should be explained with the approval form illuminated to the mother candidate. Vaginal birth after cesarean section may be recommended in appropriate cases [12].

In the study, $66.6 \%$ of women's never had an abortion and $33.4 \%$ had had an abortion at least once. In the study of Kitapçıoglu \& Yanıkerem; 10.9\% of women reported curettage at least once. The average number of abortions is $1.2 \pm 0.6$ [1] [2] [3] [4] [22]. This may be due to the fact that the research was conducted in the western region.

In the study, the majority of those who did not support curettage were housewives (63.2\%) and the majority of those who found it correct were employee $(44.6 \%)$.

In Turkey the proportion of cesarean rate is not exactly known and this proportion is known to vary between public hospitals, university hospitals and private hospitals [16].

The difference between reasons why women prefer caesarean section and gynecology obstetric clinics doing it was significant ( $\mathrm{p}=0.001, \mathrm{p}<0.05) .59 \%$ of the 32 people who preferred cesarean on their own behalf performed birth at Marsa gynecology obstetric clinic. $45.8 \%$ of those who preferred cesarean for medical reasons gave birth in Balcalı hospital. The difference was statistically significant $(\mathrm{p}=0.001, \mathrm{p}<0.05)$ between the patients who preferred cesarean on their own and the hospital that they preferred for cesarean section (Figure 2).

In recent years, it has been emphasized that the increase in the rate of recurrent cesarean, the widespread use of antenatal diagnostic techniques, and the tendency of cesarean section of pregnant and obstetric doctors [15].

The planning and implementation of training and counseling services related to pregnancy/couple subjects within the scope of prenatal care services, including all health workers providing maternity services, is recommended. It is also suggested that nurses should lead a life-long incentive application as a cost-effective approach, along with others, and guide the health policies [11].

It is believed that the thoughts of women who work will contribute in increasing normal birth rates. Considering the attitudes and beliefs of women, it is very important to give antenatal care and to be encouraged about normal birth [23].

\section{Conclusions}

As the level of education increases, the preference rate of Balcalı Hospital of Cukurova University Faculty of Medicine is increasing. Most of the non-literate people prefer Balcalı hospital because of congenital anomaly and hemorrhage.

The majority of the women who participated in the survey preferred cesarean delivery. It was determined that those who preferred cesarean on their own pre- 
ferred Adana Cukurova Birth and Child Hospital Hospital gynecology obstetric clinic, and those who preferred cesarean for medical reasons preferred Balcalı Hospital of Cukurova University Medical Faculty. Here too, it seems that the majority of those who prefer Balcalı hospital for cesarean came also for medical reasons.

Most of the researchers who came to Balcalı to learn about caesarean section and abortion found that Balcalı was again preferred by those with high education level and employees.

Unwanted pregnancies was mostly found to be aborted in Adana Cukurova Birth and Infant Care Hospital.

Most women have stated that even if it is risky for women health they can make an abortion if they have to or when remain without options. And most of them are those who came to Balcalı hospital and those who said that they cannot abort are mostly from Adana Cukurova Birth and Child Care Hospital. From here it can be said that those who came to Balcalı interact more with their environment and they have clearer ideas about abortion because of their research.

Nowadays, cesarean birth rates are increasing and there are at least 3 cesarean births around every woman as we mentioned. While $18.7 \%$ of the participants had 1 normal birth, $37.5 \%$ had 1 cesarean birth. While $51.4 \%$ of the participants chose cesarean on their own will, $8.1 \%$ had to have a cesarean section for medical reasons.

In the environment in which the research was done shows that reasons why in every 2 females 1 had an abortion are low socio-economic level and inadequate education. Effective family planning training should be provided.

Our country policies aimed to protect women and children's health by preventing risky pregnancies and those policies introduced allow families to freely and consciously make choices about their fertility by providing the necessary information and services. Nevertheless, the utilization rates of family planning methods have not yet reached the desired level. One of the most important ways to increase this rate is to educate people. On the other hand, education can be more successful if it is provided needed.

\section{Conflicts of Interest}

The author declares no conflicts of interest regarding the publication of this paper.

\section{References}

[1] WHO (2006) Reproductive Health and Research. Reproductive Health Indicators Guidelines. WHO Library Cataloguing-in-Publication Data. 1-13, 13-15.

[2] UNFPA. http://www.unfpa.org.tr/turkeytr/ureme.htm

[3] UNICEF (2008) Progress for Child. A Report Card on Maternal Mortality. 36, 46. http://www.childinfo.org/files/progress for children maternalmortality.pdf

[4] H.U. Institute of Population Studies (2004) TDHS 2003. Fertility, Chapter 4, 13. https://dhsprogram.com/pubs/pdf/FR160/FR160.pdf 
[5] Uran B. Birth by Caesarean. http://www.genetikbilimi.com/genbilim/sezaryan.htm

[6] http://www.hastane.com.tr/sezeryan-Nedir.html

[7] http://www.kurtaj.info/kurtaj gebelik sonlandirma.html

[8] Yılmaz M. Yürek sızlatan kürtaj hikayeleri (Turkish) [Heartbreaking Abortion Stories]. https://forum.memurlar.net/konu/64028/

[9] http://www.kadinlarkulubu.com/aile-planlamasi/176929-kurtaj-dogum-kontrol-yon temi-degildir.html

[10] Yıldız, Ş., Çaypınar, S.S., Cengiz, H., Dağdeviren, H. and Kanawat, A. (2014) Awareness and Perceptions of Turkish Women towards Delivery Methods. Journal of Clinical and Experimental Investigations, 5, 173-178. https://doi.org/10.5799/ahinjs.01.2014.02.0385

[11] Gözükara, F. and Eroğlu, K. (2008) Factors That Affect the Choices of Primipars on the Mode of Delivery. Journal of Hacettepe University School of Nursing, 1, 32-46.

[12] https://www.acog.org/Womens-Health/Cesarean-Delivery?IsMobileSet=false

[13] Turkey Demographic and Health Survey (2008) Hacettepe University Population Survey Institute, Ankara October 2009. http://www.hips.hacettepe.edu.tr/TNSA2008-AnaRapor.pdf

[14] Eskicioğlu, F., Hasdemir, P.S., Çelik, H. and Koyuncu, F.M. (2014) The Effect of Health Policies on Physicians' Decisions to Perform Caesarean Sections: Evaluation of a Secondary Health Institution. Pamukkale Tip Dergisi, 7, 119-123. https://doi.org/10.5505/ptd.2014.85520

[15] Özkaya, O. (2005) Birth Rates and Cesarean Indications at Süleyman Demirel University Obstetrics and Gynecology Clinic through a 5-Year Period. S.D.U. Faculty of Medicine Bulletin, 12, 36-39.

[16] Güngör, İ., Gökyıldız, Ş. and Nahcivan, N.Ö. (2004) A Group of Caesarean Births Have Opinions about Birth and Problems They Have Experienced in the Early Period after Birth. Istanbul University FNHYO Journal, 13, 185-197.

[17] Yalınkaya, A., Bayhan, G., Kale, A. and Yayla, M. (2003) 20 Years Cesarean Section and Indications in Dicle University. Turkiye Klinikleri Journal of Gynecology $\mathrm{Ob}$ stetrics, 13, 356-360.

[18] Şahin, S., Özdemir, K., Ünsal, A., Cevrioğlu, A.S. and Sevimli, D. (2013) Assessment of Delivery Choice and Opinions on Delivery of a Group of Pregnant Women. Ylldırım Beyazıt University Nursing e-Journal, 1, 28-38.

[19] Sayıner, F.D., Özerdoğan, N., Giray, S., Özdemir, E. and Savc1, A. (2009) Identifying the Women's Choice of Delivery Methods of and the Factors That Affect Them. Journal of Perinatology, 17, 104-112.

[20] İğde, F.A.A. (2004) Normal Vaginal Delivery after Cesarean Section. STED, 13, 137-139. (In Turkish)

[21] http://www.turkcebilgi.net/saglik/kadin-sagligi/normal-dogum-mu-sezaryen-mi-23 3408.html

[22] Kitapçıŏlu, G. and Yanıkkerem, E. (2008) Reproductive History, Family Planning Behaviour and Postpartum Counseling of the Women Who Had Delivery in Manisa Maternity and Childcare Hospital. Ege Journal of Medicine, 47, 87-92.

[23] Duran, E.T. and Atan, Ş.Ü. (2011) Qualitative Analysis of Women's Views on Cesarean/Vaginal Birth. General Medical Journal, 21, 83-88. 